\title{
Fever in pregnancy and its maternal and fetal outcomes
}

\author{
Vibha S. More* \\ Department of Obstetrics and Gynecology, KEM Hospital, Mumbai, Maharashtra, India
}

Received: 02 October 2017

Accepted: 31 October 2017

\author{
*Correspondence: \\ Dr. Vibha S. More, \\ E-mail: vibha.more@gmail.com
}

Copyright: $\odot$ the author(s), publisher and licensee Medip Academy. This is an open-access article distributed under the terms of the Creative Commons Attribution Non-Commercial License, which permits unrestricted non-commercial use, distribution, and reproduction in any medium, provided the original work is properly cited.

\begin{abstract}
Background: Contemporary obstetrics has witnessed improved maternal and fetal outcomes, owing to several advances. Any source of maternal hyperthermia that results in significant core temperature increase $\left(>38.9^{\circ} \mathrm{C}\right)$, could potentially affect the fetus. Hence a study was planned to know the effect of fever on maternal and fetal outcome.

Methods: This was a retrospective cohort analysis of case-records, of patients admitted in the Department of Obstetrics and Gynecology at tertiary care centre, Mumbai, between May 2007 and October 2009. The main parameters of assessment included incidence of fever in pregnancy, causes of fever, effect of episode(s) of fever on maternal and fetal outcomes, effect of specific infection on maternal and fetal outcomes, impact of fever on antepartum, intrapartum and postpartum phases

Results: The incidence of fever was $10.5 \%$. the common cause of fever was malaria (15\%), urinary tract infection $(14 \%)$, viral (14\%), respiratory tract infection (18\%), and typhoid (7\%). Seventy eight percent had fever in third trimester. The most common antenatal complication observed was preterm (13\%), premature rupture of membrane $(12 \%)$, oligohydramnios $(8 \%)$, intrauterine growth retardation $(26 \%)$. The rate of LSCS was $13 \%$ in study group and the most common indication was fetal distress and meconium stained amniotic fluid.

Conclusions: In the present study on fever during pregnancy and its maternal and fetal outcomes, fever was associated with a definite impact on maternal and fetal outcomes. Preterm and IUGR were the most common fetal complications. Duration of fever was linearly associated with poor outcomes. Different causes of fever also had different impact on maternal and fetal outcome. Preterm IUGR, MSAF were more common with malaria and tuberculosis. Abortion was more commonly seen in first trimester fever, whereas preterm, PROM in the third trimester fever. Hence it is suggested that fever during pregnancy needs to be promptly investigated and treated to have a better outcome.
\end{abstract}

Keywords: IUGR, Fever, Meconium

\section{INTRODUCTION}

Contemporary obstetrics has witnessed improved maternal and fetal outcomes, owing to several advances. Early detection and prompt management of fever, has been a leading contributor to these developments. Any source of maternal hyperthermia that results in significant core temperature increase $\left(>38.9^{\circ} \mathrm{C}\right)$, could potentially affect the fetus. Consequences of hyperthermia depend on the extent and duration of temperature elevation, timing of the exposure in pregnancy, and possibly on maternal nutritional status, comorbidities, medications, genetic background, and several other factors. Maternal fever is implicated as human teratogen. Even short exposure of maternal temperature has been reported to lead to cell disruptions, vascular disruption and placental infarction, which affect the risk of structural and functional defect in the offspring. ${ }^{1,2}$ An episode of fever is of common occurrence in pregnancy. A surveillance of the effect and outcomes of fever in pregnancy, provides finer insights of 
clinical epidemiology, and facilitates optimum prioritization of efforts and resources. This study was aimed to assess the epidemiology of fever in pregnancy, in patients visiting a tertiary referral institute in Mumbai, India.

\section{METHODS}

This was a retrospective cohort analysis of case-records, of patients admitted in the Department of Obstetrics and Gynecology at tertiary care centre, Mumbai, between May 2007 and October 2009.

The main parameters of assessment included:

- Incidence of fever in pregnancy

- Causes of fever

- Effect of episode(s) of fever on maternal and fetal outcomes

- Effect of specific infection on maternal and fetal outcomes

- Impact of fever on antepartum, intrapartum and postpartum phases

100 complete case-records of such patients, who could be followed up till the end of pregnancy, were available for assessment ('Study Group'). A 'Control Group' of 100 sequentially admitted patients, who did not have fever during pregnancy, was also included.

All patients with fever during pregnancy were admitted in the ANC ward. Detailed history and clinical examination were performed. Patients' vitals were monitored, and necessary investigations were carried out. After correlating the clinical findings and investigations, and the response to empirical therapy, diagnosis was established. Patient were treated, and discharged if asymptomatic and afebrile for 72 hours, with advice on regular ANC follow up. Patients were followed till delivery and till discharge. Maternal and fetal outcomes were studied.

Maternal parameters for assessment, included age, parity, antenatal high-risk factors, mode of delivery, duration of gestation at the time of first episode of fever, cause of fever, duration of fever, specific therapy given and response to therapy and maternal outcome. Fetal parameters for assessment included birth-weight, neonatal outcome, indication and duration of NICU admission. Descriptive statistics were used for assessment.

\section{RESULTS}

The groups were well-matched at baseline, for age-group and parity. The median age-group was 21-25 years, and median parity was G2, in each group. 45 cases were primigravida in the study group. The causes of fever in the study group are enlisted in Table 1.
Table 1: Distribution of study group according to cause of fever.

\begin{tabular}{|ll|}
\hline Diagnosis & Study $(\mathbf{n}=\mathbf{1 0 0 *})$ \\
\hline Malaria & 15 \\
\hline Urinary tract infection & 14 \\
\hline Viral & 14 \\
\hline Upper respiratory tract infections & 11 \\
\hline Lower respiratory tract infections & 7 \\
\hline Typhoid & 7 \\
\hline Fever responding to antimalarial & 9 \\
\hline Tuberculosis & 5 \\
\hline Dengue & 5 \\
\hline Leptospirosis & 3 \\
\hline Fever associated with vaginitis & 3 \\
\hline Gastroentritis & 3 \\
\hline Chicken pox & 3 \\
\hline Syphilis & 2 \\
\hline Undiagnosed fever & 1 \\
\hline Hepatitis & 2 \\
\hline *Some patients had $>1$ diagnoses, hence the total number is \\
\hline 100. \\
\hline
\end{tabular}

The incidence of fever was high in third trimester $(\mathrm{n}=$ $78)$, followed by first trimester $(n=12)$; there were 10 cases in second trimester. 2 cases in the third trimester, had intrapartum fever; both were terminal events, one was accompanied by fresh still-birth, and other was accompanied by neonatal death at day 3 of life.

Majority of patients had fever lasting for $\leq 7$ days $(n=62$ for 1-3 days; $n=31$ for 4-7 days). 4 patients had fever lasting for 7-10 days, and only 3 patients had fever of $>10$-day duration. The duration of fever, and associated fetal outcomes, are summarized in Table 2. A linear association was observed between the duration of fever and fetal outcomes; $62.2 \%, 69.8 \%, 85.7 \%, 100 \%$ of cases suffered from adverse outcomes in the respective subgroups, based on the duration of fever ( $<3$ days, 3-5 days, 6-10 days, $>10$ days).

Table 2: Duration of fever and associated fetal outcomes.

\begin{tabular}{|lllll|}
\hline Duration & IUGR & Preterm & MSAF & A bortion \\
\hline <3days (37) & 10 & 5 & 3 & 5 \\
\hline 3-5 days (53) & 17 & 5 & 11 & 7 \\
\hline 6-10 days (7) & 2 & 2 & 1 & 1 \\
\hline$>$ 10 days (3) & 1 & 1 & 0 & 1 \\
\hline
\end{tabular}

Antenatal complications, in the study and control groups, are summarized in Table 3. The most common antenatal complication seen was IUGR, preterm, followed by PROM oligohydramnios, postdatism, and PIH. The incidence of complications associated with fever like preterm, oligohydramnios, IUGR, fetal distress were higher in study group, but other complication was comparable. Mean birth weight in the Study group was $2.4 \mathrm{Kg}$, and in Control group, was $2.6 \mathrm{Kg}$. Low birth- 
weight $(<2.5 \mathrm{Kg})$ was observed in $49 \%$ of cases in the study group, compared to $35 \%$ of cases in control. The relative risk of low birth-weight was significant $40 \%$ higher in the study group, compared to control group $(\mathrm{p}=0.048)$.

Table 3: Antenatal complications.

\begin{tabular}{|lll|}
\hline $\begin{array}{l}\text { Antenatal } \\
\text { complication }\end{array}$ & $\begin{array}{l}\text { Study } \\
(\mathbf{n}=\mathbf{1 0 0})\end{array}$ & $\begin{array}{l}\text { Control } \\
(\mathbf{n}=\mathbf{1 0 0})\end{array}$ \\
\hline Preterm & 13 & 6 \\
\hline Oligohydraminos & 8 & 2 \\
\hline IUGR & 29 & 20 \\
\hline Postdatism & 7 & 6 \\
\hline PIH & 8 & 7 \\
\hline Polyhydraminos & 4 & 1 \\
\hline Fetal distress & 5 & - \\
\hline Anaemia & 4 & 5 \\
\hline Prom & 12 & 9 \\
\hline Scar Tenderness & 3 & 1 \\
\hline Jaundice & 2 & - \\
\hline GDM & 1 & - \\
\hline None & 38 & 62 \\
\hline
\end{tabular}

The modes of deliveries, in the study and control groups, along with the relative risks for each subgroup, are summarized in Table 4. The fetal outcomes are described in Table 5 .

Table 4: Distribution of study group and control according to mode of delivery.

\begin{tabular}{|llll|}
\hline $\begin{array}{l}\text { Mode of } \\
\text { delivery }\end{array}$ & $\begin{array}{l}\text { Study } \\
(\mathrm{n}=\mathbf{1 0 0})\end{array}$ & $\begin{array}{l}\text { Control } \\
(\mathrm{n}=\mathbf{1 0 0})\end{array}$ & $\begin{array}{l}\text { Relative risk } \\
(\mathrm{p} \text {-value })\end{array}$ \\
\hline FTND & 54 & 90 & $\begin{array}{l}4.6 \\
\left(<0.0001^{*}\right)\end{array}$ \\
\hline LSCS & 13 & 5 & $\begin{array}{l}2.6 \\
(0.06, \mathrm{~ns})\end{array}$ \\
\hline PTVD & 13 & 5 & $\begin{array}{l}2.6 \\
(0.06, \mathrm{~ns})\end{array}$ \\
\hline $\begin{array}{l}\text { FTVD } \\
\text { (abnormal) }\end{array}$ & 5 & 0 & $\begin{array}{l}11 \\
(0.1, \mathrm{~ns})\end{array}$ \\
\hline Abortion & 14 & 0 & $\begin{array}{l}29 \\
(0.019 *)\end{array}$ \\
\hline
\end{tabular}

*Significant; NS: Non-significant

Table 5: Distribution of study group and control according to fetal outcome.

\begin{tabular}{|lll|}
\hline $\begin{array}{l}\text { Fetal outcome } \\
\text { Healthy with }\end{array}$ & Study $(n=100)$ & Control $(n=100)$ \\
mother & 47 & 77 \\
\hline NICU & 37 & 23 \\
\hline Abortion & 14 & 0 \\
\hline FSB & 1 & 0 \\
\hline
\end{tabular}

Of the 13 LSCS in study group, 4 were indicated for fetal distress, 2 for thick MSAF, 1 for APH, 3 for scar tenderness, 3 for (oligohydramnios with breech, precious pregnancy with GDM, PIH with PROM). In the control group, no case was indicated for significant fetal distress.

Healthy fetal and maternal outcomes were 2.3-fold more common in the control group ( $\mathrm{p}<0.0001)$, whereas the relative-risk of NICU admission was 1.6-fold higher in the study group $(\mathrm{p}=0.034)$. Of 37 NICU admissions in the study group, 1 death was observed; there were no deaths in the control group. Total perinatal mortality was $2 \%$ (1 FSB and 1 NND on day 3 of life).

In the study group, amongst patients with malaria infection, $53.43 \%$ of neonates required NICU admission, and $13.34 \%$ of cases had abortions. In patients with UTI, $50 \%$ of neonates were healthy with mother, whereas $28.57 \%$ of cases had abortions. In patients with viral infections, $50 \%$ of neonates were healthy with mother, and $42.86 \%$ required NICU admission. In patients with vaginitis, $66.66 \%$ had spontaneous abortion. NICU admission was more common in the Study group, as compared to control; the most common cause of NICU admission was MSAF (15\%), followed by preterm status (10\%), birth asphyxia (3\%) and PROM (2\%).

$15 \%$ cases in study group were diagnosed with malaria, of which 4 were IUGR, 2 had MSAF, 3 had preterm, and 3 had spontaneous abortion. 9 multigravida and 6 primigravida cases had malaria. 13 of the 15 cases were diagnosed positive for vivax, and 2 were positive for falciparum. Malaria was more common in third trimester $(\mathrm{n}=8)$, followed by second trimester $(\mathrm{n}=5)$ and first trimester $(n=2)$. Amongst the 9 febrile pregnant patients who responded to antimalarial treatment, but had negative peripheral smear, 1 IUGR, 2 MSAF, 2 abortions, 1 preterm and 2 'healthy with mother' outcomes were observed. Number of patients, who were suspected to have malaria and responded to antimalarials, was also more in third trimester $(n=6)$ followed by second trimester $(n=2)$ and first trimester $(n=1)$.

LSCS rate was higher in the study group, in cases with viral infections, followed by TB, URTI and UTI. Abortion was more common in cases with vaginitis, UTI, and leptospirosis.

Perinatal mortality was observed in viral and undiagnosed fever. Incidence of MSAF was higher in malaria and lower respiratory tract infections, whereas preterm birth and IUGR were more with most of the infections.

\section{DISCUSSION}

The present study performed in a tertiary-care centre in Mumbai, provides insights into the contemporary epidemiology of fever during pregnancy. The incidence of malaria observed in our study, was lesser as compared to the $48 \%$ incidence observed by Hay and colleagues in 2004. In a study conducted by Chamber and colleagues in 
1998 , the incidence of fever due to viral infection was $26 \%$, URTI was $21.8 \%$, and UTI was $15 \%$. $^{3}$

In the present study, the incidence of fever was higher in the third trimester. This contrasts with the observation by Dick Lyn, who observed $79 \%$ of cases of fever in the first trimester. $^{3}$

In present study the incidence of fever was high in the primigravida; hence it suggests that women getting pregnant for first time need more education for prevention. This observation correlates with the study conducted by Chambers CD et al the fever group consisted $38 \%$ of primigravida. ${ }^{3}$ Fever is known to cause preterm labor, as well as FSB. In the present study, the common antenatal complications observed were preterm labor and premature rupture of membrane. In a study conducted by Zeeman et al, the incidence of preterm labor was found to be $33 \%$, whereas Chambers CD et al found it to be $28 \%{ }^{3}$ Cotch and associates observed an increased incidence of preterm labor in neonates, of women with chorioamnionitis $(30 \%))^{2}$ The observed incidence for these complications was much lower in our study, as compared to that quoted in literature.

Nearly half of the cases were low birth-weight. Cotch and associates observed that neonates of women with chorioamnionitis had increased incidence of LBW (40\%), comparable to the present study. ${ }^{4}$

In the present study, the incidence of abortion (14\%) was higher compared to the study conducted by Chambers CD $(10 \%)$, but lower than that observed by Jennie-Kline $(18 \%)$. Abortion seems to be the most frequent fetal complication and fetal loss. ${ }^{3}$

Desai $\mathrm{M}$ et al, observed maternal anaemia in $38 \%$, low birth weight in $43 \%$, and perinatal mortality in $27 \%$ of cases. $^{5}$ Saba N, observed that $40 \%$ of malaria cases happened in second trimester, and falciparum (76\%) malaria was more common than vivax; $14 \%$ had spontaneous abortion, 9\% had neonatal death, $6 \%$ were preterm, $59.75 \%$ were multigravida. ${ }^{6}$ Surg Lt found that parasitaemia was present in $6.5 \%$, falciparum was more common $(48.2 \%)$, malaria was more commonly in second trimester $(62.9 \%)$, spontaneous abortion was seen in $10 \%$, preterm with low birth weight was seen in $14.8 \%$, MSAF in $25.9 \%$, fetal death, IUFD and still birth in $7.4 \%, 3.7 \%$ and $3.7 \%$ respectively. ${ }^{7}$ Maitra et al, in their study found plasmodium falciparum affecting $97.2 \%$ of cases and $71 \%$ women were primigravidae. ${ }^{8}$ The abortion rate was $100 \%$ in the first trimester and $75 \%$ in the second trimester. The overall fetal loss was $31 \%$. The incidence of maternal death was $8.4 \%$.

In present study, 5 cases had tuberculosis, of which 2 had IUGR, 2 were preterm and 1 baby was healthy with mother. Khadilkar SS et al conducted an observational study of pregnancies with tuberculosis, with the aim of studying the pattern of the disease over a span of 10 years, and the pregnancy outcomes. ${ }^{9}$ Probably the largest published series in India which reported 153 patients of tuberculosis and pregnancy from 1991-2000 divided in two study period 1991-1995 phase 1 and 1996-2000 phase 2. The incidence was reported as $0.38 \%$ and $0.5 \%$ in the two-phase compared to the incidence of $18 \%$ in 1960 reported in the same hospital by Dr. Desmukh. The rate of low birth weight babies, including small for gestational age and preterm, was $35.5 \%$ and $41.6 \%$; the rate of still-birth was $5.3 \%$ and $2.6 \%$ respectively in the two phases of the study.

In the present study, 5 cases had dengue fever, of which 1 had $2^{\text {nd }}$ trimester spontaneous abortion, one was IUGR, and 3 neonates were healthy with mother. However, Carles $\mathrm{G}$ et al found that the rate of fetal death associated with dengue fever was $13.6 \% .^{10}$ Basurko $\mathrm{C}$ observed severe maternal consequences, including premature labour $41 \%$, premature birth $9.6 \%$, haemorrhage during labour $9.3 \%$, retroplacental clot $1.9 \%$, and fetal consequence like prematurity $20 \%$, intrauterine fetal demise $3.8 \%$, fetal distress $7.5 \%$, maternal fetal transmission 5.6\%, and neonatal death $1.9 \%$. Thrombocytopenia poses a real threat to mother. ${ }^{11}$

In the present study, of the 14 cases of urinary tract infection, 4 had spontaneous abortion, 2 had preterm delivery, 1 had IUGR with MSAF, and 2 had PROM. UTI was more common in third trimester (7), and in multigravida (8). Urine culture was positive in 8 cases and Escherichia coli was the most common organism (5).

Nath $\mathrm{G}$ et al observed that third trimester was associated with highest number of UTI cases (11.9 percent, 27/226), followed by second (7.5 percent, 16/212), and first (5.7 percent, 6/104). ${ }^{12}$ Primigravida had higher number of culture positivity (11.47 percent, 28/244), compared to multiparous women (7.04 percent, 21/298). Approximately 35 percent (17/49) of the culture positive women were asymptomatic. Escherichia coli was the commonest isolate (30.6 percent, 15/49). Among the fetal complications, low birth weight babies were significantly more frequent in patients with UTI.

\section{CONCLUSION}

In the present study on fever during pregnancy and its maternal and fetal outcomes, fever was associated with a definite impact on maternal and fetal outcomes. Preterm and IUGR were the most common fetal complications.

Duration of fever was linearly associated with poor outcomes. Different causes of fever also had different impact on maternal and fetal outcome. Preterm IUGR, MSAF were more common with malaria and tuberculosis. Abortion was more commonly seen in first trimester fever, whereas preterm, PROM in the third trimester fever. Hence it is suggested that fever during pregnancy needs to be promptly investigated and treated to have a better outcome. 
Funding: No funding sources

Conflict of interest: None declared

Ethical approval: The study was approved by the Institutional Ethics Committee

\section{REFERENCES}

1. Edwards MJ. Hyperthermia and fever during pregnancy. Birth Defects Research Part A: Clinical and Molecular Teratology. 2006;76(7):507-16.

2. Edwards MJ, Saunders RD, Shiota K. Effect of heat on embryos and fetuses. Int $\mathbf{J}$ Hyperthermia. 2003;19(3):295-324

3. Chamber CD, Johnson KA, Dick LM, Felix RJ, Jones KL. Maternal fever and birth outcome: a prospective study. Teratol. 1998;58:251-7.

4. Cotch MF, Pastorek JG, Nugent RP, Hillier SL, Gibbs RS, Martin DH, et al. Trichomonas vaginalis associated with low birth weight and preterm delivery. Sex Transm Dis. 1997;24:352.

5. Kline J, Stein Z, Susser M, Warburton D. Fever during pregnancy and spontaneous abortion. Am J Epidemiol. 1985;121(6):832-42.

6. Saba N, Sultana A, Mahsud I. Outcome and complication of malaria in pregnancy. Gomal $\mathrm{J}$ Med Sci. 2008;6(2):98-101.
7. Chawla S, Manu V. Malaria in pregnancy. MJAFI. 2007;63:147-8.

8. Mitra N, Joshi M, Hazra M. Maternal manifestation of malaria in pregnancy: a review. India J Mater Child Health. 1993;4:98-101.

9. Khadilkar SS, Saraiya UB. Tuberculosis in pregnancy: a ten-year overview. J Obstet Gynecol India. 2003;53(5):453-7.

10. Charles G, Peiffer H, Talarmin A. Effect of dengue fever during pregnancy in French Guiana. Clin Infect Dis. 1999;28(3):637-40.

11. Basurko C, Carles G, Youssef M, Guindi WE. Maternal and fetal consequence of dengue fever during pregnancy. Eur J Obstet Gynaecol Reprod Biol. 2009;147(1);29-32.

12. Nath G, Chaudhary M, Prakash J, Pandey LK, Singh TB, Jai P. Urinary tract infection in pregnancy and fetal outcome. Indian J Med Microbiol. 1996;14(3):158-60.

Cite this article as: More VS. Fever in pregnancy and its maternal and fetal outcomes. Int J Reprod Contracept Obstet Gynecol 2017;6:5523-7. 